\title{
Nicotine and Kainic Acid Effects on Cortical Epileptic Afterdischarges in Immature Rats
}

\author{
V. RILJAK ${ }^{1}$, D. MAREŠOVÁ ${ }^{1}$, K. JANDOVÁ ${ }^{1}$, J. POKORNÝ ${ }^{1}$ \\ ${ }^{1}$ Institute of Physiology, First Faculty of Medicine, Charles University in Prague, Czech Republic
}

Received November 22, 2011

Accepted June 8, 2012

On-line August 8, 2012

\begin{abstract}
Summary
Aim of the study was to test the effect of nicotine (NIC) and kainic acid (KA) co-treatment in immature rats. Male Wistar albino rats (two different age groups) were chosen for the study. Experiments started on postnatal day (PD) 8 or 21 and animals were treated twice a day for three days with nicotine, fourth day KA was administered. Animals at PD12 (PD25 respectively) were examined electrophysiologically for cortical epileptic afterdischarges (ADs). First cortical ADs in PD12 animals were longer, when compared to PD25 rats (group treated with both substances). Nor NIC or KA treatment affected the length of discharges in PD12 rats. Older experimental group exhibited the shortening of the first ADs (group treated with NIC and KA, compared with groups exposed to single treatment). Few changes were found in KA treated group $-2^{\text {nd }}$ and $4^{\text {th }} A D$ s were shorter when compared with first ADs. These results demonstrate that NIC treatment played minor role in seizure susceptibility of PD12 rats, sensitivity to NIC differs during ontogenesis and subconvulsive dose of KA influenced the length of discharges only in PD25 animals.
\end{abstract}

\section{Key words}

Evoked potentials - Afterdischarges - Nicotine - Kainic acid • Development $\bullet$ Rat

\section{Corresponding author}

Vladimir Riljak, Institute of Physiology, First Faculty of Medicine, Charles University in Prague, Albertov 5, CZ-128 00, Prague 2, Czech Republic. E-mail: vladimir.riljak@If1.cuni.cz

\section{Introduction}

Testing the proconvulsant or anticonvulsant properties of NIC is of high importance because the role of NIC in process of epileptogenesis is still unclear. That is crucial foremost for patient with epilepsy who smokes, because NIC is suspected to influence the results of antiepileptic therapy (Sood et al. 2011). NIC is highly addictive substance, delivered via cigarette smoke or transdermal patches and exerting variety effects on learning, memory, mood and regulation of stress and anxiety (Ferrea and Winterer 2009). NIC is as well of considerable scientific and medical significance, because of its ability to influence perturbation of some physiological parameters (Pelissier et al. 1998), cortex excitability (Riljak et al. 2010) and consequences of seizure inducing drugs (Riljak et al. 2007, Borlongan et al. 1995). Different experiments confirmed that NIC is effective against neuronal damage related to $\beta$-amyloid formation and protects the nigrostriatal system in various model of Parkinsonism (Buckingham et al. 2009). Majority of above mentioned NIC properties is associated with activation of neuronal nicotinic acetylcholine receptor - ligand gated cationic pentameric channels distributed throughout the central nervous system (Nai et al. 2003, Role and Berg 1996).

$\mathrm{KA}$ is rigid analogue of glutamate causing massive neuronal depolarization and this effect may finally lead to functional overload of neuronal circuits and cell death (Ben-Ari and Cossart 2000, Sperk 1994). One of the most sensitive structures is hippocampus, because this part of CNS exhibits high density of kainate receptors (Huettner 2003), thereby administration of kainate causes the massive degeneration of CA3 and CA1 fields of hippocampus (Riljak et al. 2007, Schmued and Hopkins 2000), partially by direct toxic effect and partially by seizure generating epileptiform seizures predominantly in CA3 region of hippocampus (Ben-Ari 
and Cossart 2000). Seizures induced by KA are able to propagate to other limbic structures leading to pattern similar to those one observed in human temporal lobe epilepsy (Ben-Ari 1985, Sperk 1994). On the other hand, when KA is administered in subconvulsive dose it mimics the seizure pattern similar to those observed in human complex partial seizures without secondary generalization.

Previous studies (Borlongan et al. 1995, Riljak et al. 2007, Kim et al. 2000) showed that administration of NIC is capable to protect the hippocampal neurons against the KA induced damage and that NIC could influence the seizure susceptibility and shorten the length of ADs (Riljak et al. 2010).

Therefore, the aim of present study was to examine, whether NIC administered in low consecutive doses might have positive/negative cooperative actions on length and pattern of ADs influenced by single dose of KA. The present study aimed at the evaluation of the pro-/anti-convulsant effect of NIC during development in order to assess the health risks associated with its chronic administration in patient suffering from complex partial seizures. Susceptibility of brain cortex was tested by elicitation of ADs. This model allows observing pattern, type and duration of ADs elicited by repeated electrical stimulation and tests the involvement of desired substance in generation and arrest of cortical seizures (Mareš et al. 1982-1983, Marešová et al. 2010).

\section{Methods}

\section{Animals}

Experiments were performed on immature male Wistar albino rats of our own breed. Rat pups entered the experiment on PD8 and PD21. The day of birth was counted as 0 . Animals were housed at a constant temperature $\left(23 \pm 1{ }^{\circ} \mathrm{C}\right)$ and relative humidity $(60 \%)$ with a fixed $12 \mathrm{~h} \mathrm{light/dark} \mathrm{cycle} \mathrm{(with} \mathrm{lights} \mathrm{on} \mathrm{at} \mathrm{07:00)} \mathrm{and}$ fed (or their mothers) with food and water ad libitum. On the testing day animals were transported into the experimental room, weighed, marked and randomly assigned into particular experimental groups. All tests were performed between $9 \mathrm{AM}$ and 2 PM. All experiments were carried out in accordance with the European Communities Council Directive (86/609/EEC) and in agreement with the guidelines of the Animal Protection Law of the Czech Republic.

\section{Drugs treatment and experimental workflow}

Each litter was divided at random into group treated either with NIC, KA or both. (-)-nicotine and kainic acid were sourced from Sigma-Aldrich, dissolved in saline immediately before administration and applied in concentration $1 \mathrm{ml} / \mathrm{kg}$ of body mass. Three experimental groups have been formed (each consisted of at least 10 rat pups):

A. NIC group: animals received 2 doses of NIC per day $(0.25 \mathrm{mg} / \mathrm{kg}$, i.p.) at 9:30 AM and 2:00 PM for three day starting on PD8 (or PD21). On PD11 (or PD24) rats received one injection of normal saline at 9:30 $\operatorname{AM}(1 \mathrm{ml} / \mathrm{kg})$.

B. KA group: animals received 2 doses of normal saline per day (1 ml/kg, i.p.) at 9:30 AM and 2:00 PM for three day starting on PD8 (or PD21). On PD11 (or $\mathrm{PD} 24)$ rats received one injection of $\mathrm{KA}(5 \mathrm{mg} / \mathrm{kg}$, i.p.) at 9:30 AM.

C. KA + NIC group: animals received 2 doses of nicotine per day $(0.25 \mathrm{mg} / \mathrm{kg}$, i.p. $)$ at 9:30 AM and 2:00 PM for three day starting on PD8 (or PD21). On PD11 (or PD24) rats received one injection of KA $(5 \mathrm{mg} / \mathrm{kg}$, i.p. $)$ at 9:30 AM.

\section{Electrophysiology}

Surgical preparation took place at PD12 or PD25 (24 hours after last treatment). Six silver electrodes were implanted epidurally through the cranium under ether anaesthesia: two stimulation electrodes (right sensorimotor cortex), three registration electrodes (left sensorimotor cortex, left and right visual cortex) and reference electrode (placed into nasal bone). Recording and other experimental manipulations were carried out after the recovery of righting and suckling reflexes (i.e. approximately $15 \mathrm{~min}$ after the surgery), then the cortical afterdischarges were elicited by stimulation of the right sensorimotor cortex. We used constant current stimulation (bipolar pulses - pulse period $1 \mathrm{~ms}$; duration of stimulation $15 \mathrm{~s}$; frequency $8 \mathrm{~Hz}$; intensity 3-5 mA, which is sufficient for ADs eliciting). The basic stimulation intensity level was set at $3 \mathrm{~mA}$. In case of no response, another stimulation of $4 \mathrm{~mA}$ was used $5 \mathrm{~min}$ after the first stimulation. The process was similarly repeated with $5 \mathrm{~mA}$ stimulation. Finally, if no epileptic graphoelements appeared after the $5 \mathrm{~mA}$ stimulation, the animal was excluded from the experiment. If a distinct response (epileptic graphoelements) was recorded, the stimulation was repeated five times at one-minute intervals (timed from the end of each seizure to the 


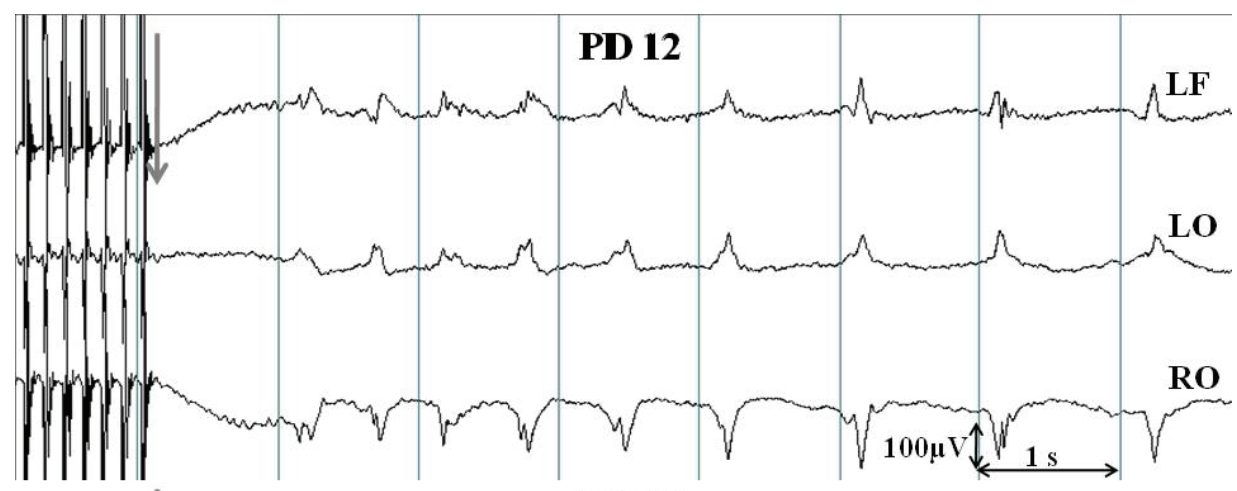

PD 25
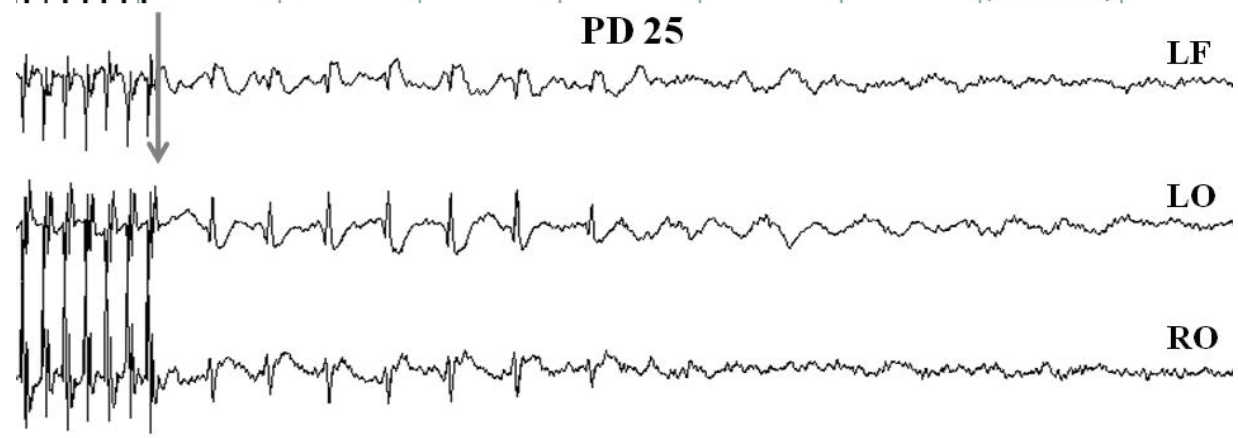

Fig. 1. Electrocorticographic recording of a cortical discharges in PD12 (upper graph) and PD25 old rat (bottom graph). Individual leads from top to bottom: Left frontal (LF), left occipital (LO) and right occipital (RO) areas, all in reference connection. Grey arrows indicate the end of stimulation. beginning of the next stimulation). The duration of evoked ADs and the shape of evoked graphoelements were recorded. Electrocorticograms were recorded 5 minutes before the very first stimulation and during whole stimulation process.

\section{Statistics}

Electrophysiological data were subjected to nonparametric tests. To compare the differences in ADs length in six subsequent stimulations in particular groups Friedman test followed by Wilcoxon signed rank test were used. To compare the differences between group A, $\mathrm{B}$ and $\mathrm{C}$ within a given session, Kruskal-Wallis test and the Mann-Whitney test were used.

\section{Results}

Stimulation of sensorimotor cortical area brought about forelimbs movements in the rhythm of stimulation. The afterdischarges in 12-day-old animals were represented by rhythmic sharp waves only, while afterdischarges in older group formed spike-and wave rhythm (Fig. 1). Clonic movements that accompanied elicited afterdischarges were synchronous with sharp ECoG graphoelements.

\section{Age-related differences in ADs length}

Duration of the first ADs in 12-day-old rats when compared with 25-day-old rats differed only in 1st ADs duration

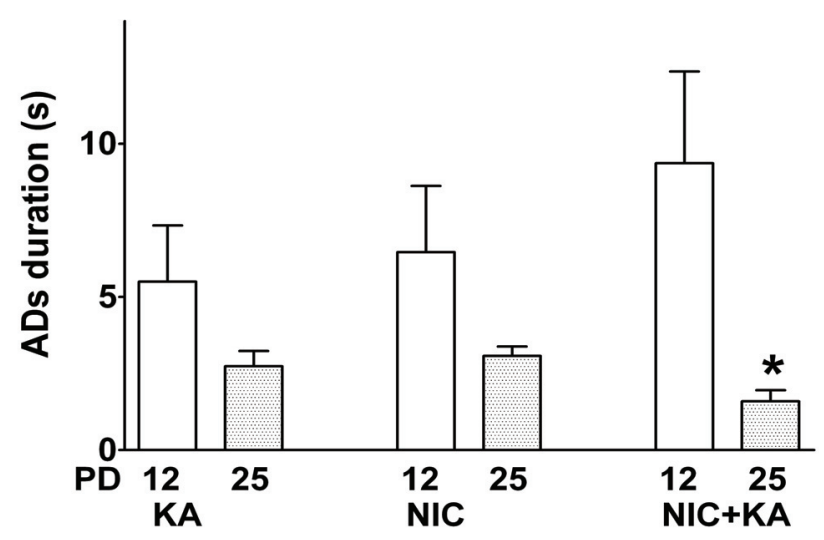

Fig. 2. Duration of first ADs in 12- and 25-day-old animals. White columns - 12-day-old rats, spotted columns - 25-day-old rats. NIC - nicotine treated groups, KA - kainic acid treated groups, NIC+KA - animals treated with both. * indicate differences significant at $p<0.05$. Results were calculated as mean \pm SEM and the error bars in graphs indicate the standard error of the mean.

group $\mathrm{C}(\mathrm{p}<0.05)$. Differences in groups A and B were statistically insignificant (Fig. 2).

\section{2-day-old-animals}

Duration ADs (comparison of the very first ADs with the other five ones) after KA administration tended to lengthen with repeated stimulation but it did not reach the level of statistical significance. Repeated administration of NIC did not demonstrate any change in 


\section{A: 12-day-old animals}

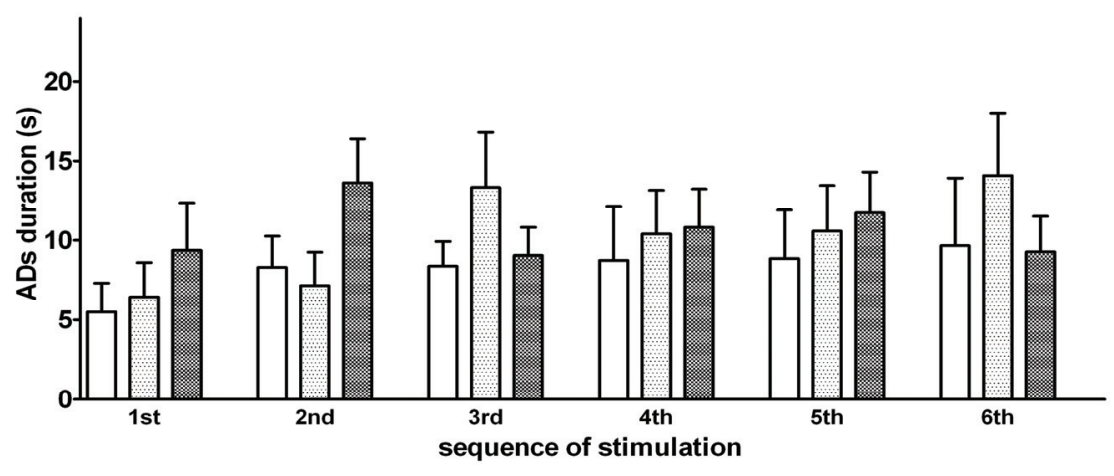

B: 25-day-old animals

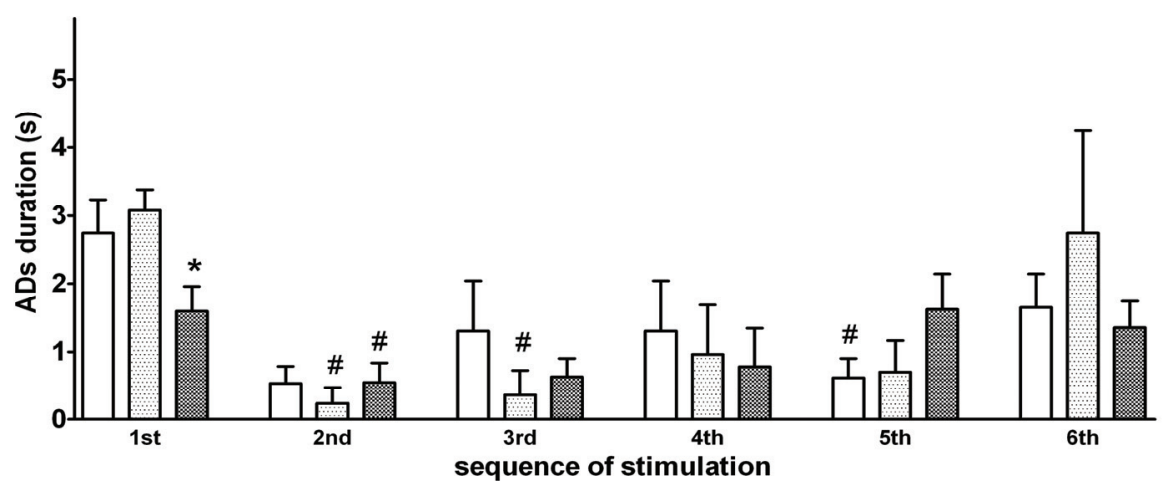

Fig. 3. Duration of ADs in 12-day-old (A) and 25-day-old (B) rats. X axis sequence of stimulation $\left(1^{\text {st }}-6^{\text {th }}\right)$. White columns - animals treated with saline and KA (i.p.). Spotted columns - animals treated with NIC (i.p.) and saline. Dark spotted columns animals treated with NIC and KA. $*$ indicates difference significant at $\mathrm{p}<0.05$ within the particular session (stimulation), \# indicate differences significant at $p<0.05$ in comparison with $A D s$ after the first stimulation. Results were calculated as mean \pm SEM and the error bars in graphs indicate the standard error of the mean. duration of subsequent afterdischarges. The same result was observed when the animals were pre-treated with NIC and after that KA was applied. No changes were found in ADs length in-between the experimental groups - different treatment did not show significant changes in particular ADs duration (Fig. 3).

\section{5-day-old-animals}

Duration of ADs (comparison of the very first ADs with the other five ones) after KA administration demonstrated decrease of ADs length after the $2^{\text {nd }}$ and $5^{\text {th }}$ stimulation (Fig. 3). Length of ADs was shorted as well after NIC treatment ( $2^{\text {nd }}$ and $3^{\text {rd }}$ stimulation). No changes were observed in group C. Analysis of the results inbetween the experimental group's revealed significant difference after the first stimulation. The first ADs duration was significantly shorter in group $\mathrm{C}$, when compared either with group A or B $(\mathrm{p}<0.05)$.

\section{Discussion}

The present study examined the effect of NIC and KA co-treatment on seizure susceptibility in model of repeated electrical stimulation of brain cortex. The experimental pattern of six repeated stimulations with short inter-stimulus interval has been used in our laboratory for many years and normative data are at our disposal (Marešová and Mareš 1999, Riljak et al. 2010). The EEG pattern was formed by rhythmic sharp waves in PD12 group, while the spike-and-wave rhythm was recorded in PD25 group. These findings are in agreement with the development of rhythmic phenomena of thalamo-cortical origin (Mareš et al. 1982).

Our experiment didn't demonstrate any effect of NIC or KA treatment on ADs length in younger experimental animals (Fig. 3). This finding could be explained as follows: before PD14 KA neither has any effect on prolongation of ADs duration (Kubová et al. 2001), nor is capable to evoke spontaneous recurrent seizures (Stafstrom et al. 1992) - electrical stimulation and KA treatment are probably not synergic epileptogenic stimuli at this particular level of rat development. Secondly, NIC dose chosen by us was probably low to show any effect on ADs duration in 12-day-old animals. Used dose was settled according to our previous experiments (Hralová et al. 2010, Riljak et al. 2010, 
Riljak et al. 2011). In latter studies much older animals were used (PD35) and it seems to be very probably that sensitivity to NIC differs during development.

In PD25 group treated with NIC+KA first ADs length was shorten when compared either with KA treated group or group treated with NIC. The following five stimulation didn't show any differences in ADs length (Fig. 2, 3). The arresting mechanisms of PD25 animals were probably exhausted after the very first electrical stimulation.

Mutual comparison of ADs length between age groups confirmed, that the average duration of ADs was longer in younger animals, while reached the level of statistical significance only in group treated with both substances (Fig. 2). ADs duration of naive immature rats (PD12) in various experimental designs is longer, when compared with older rats - this fact is known for decades (Moshe et al. 1993) reflecting the nonlinearity of epileptogenesis, where many "developmental windows" of relatively higher resistance to epileptogenic stimuli appear (Schwartzkroin 1984). This age-related difference disappeared after NIC or KA administration, but could be still demonstrate when both substances are used. In conclusion the NIC treatment played minor role in seizure susceptibility of PD12 rats, sensitivity to NIC differed during ontogenesis and subconvulsive dose of KA influenced the length of discharges only in PD25 animals.

\section{Conflict of Interest}

There is no conflict of interest.

\section{Acknowledgements}

This study was supported by grants by GACR 305/09/P136 and PRVOUK-P34/LF1/7.

\section{References}

BEN-ARI Y: Limbic seizure and brain damage produced by kainic acid: mechanisms and relevance to human temporal lobe epilepsy. Neuroscience 14: 375-403, 1985.

BEN-ARI Y, COSSART R: Kainate, a double agent that generates seizures: two decades of progress. Trends Neurosci 23: 580-587, 2000.

BORLONGAN CV, SHYTLE RD, ROSS SD, SHIMIZU T, FREEMAN TB, CAHILL DW, SANBERG PR: (-)-nicotine protects against systemic kainic acid-induced excitotoxic effects. Exp Neurol 136: 261-265, 1995.

BUCKINGHAM SD, JONES AK, BROWN LA, SATTELLE DB: Nicotinic acetylcholine receptor signalling: roles in Alzheimer's disease and amyloid neuroprotection. Pharmacol Rev 61: 39-61, 2009.

FERREA S, WINTERER G: Neuroprotective and neurotoxic effects of nicotine. Pharmacopsych 42: 255-265, 2009.

HRALOVÁ M, MAREŠOVÁ D, RILJAK V: Effect of the single-dose of nicotine- administration on the brain bioelectrical activity and on behaviour in immature 12-day-old rats. Prague Med Rep 111: 182-190, 2010.

HUETTNER JE: Kainate receptors and synaptic transmission. Prog Neurobiol 70: 387-407. 2003.

KIM HC, JHOO WK, KO KH, KIM WK, BING G, KWON MS, SHIN EJ, SUH JH, LEE YG, LEE DW: Prolonged exposure to cigarette smoke blocks the neurotoxicity induced by kainic acid in rats. Life Sci 66: 317-326. 2000.

KUBOVÁ H, MIKULECKÁ A, HAUGVICOVÁ R, LANGMEIER M, MAREŠ P: Nonconvulsive seizures result in behavioral but not electrophysiological changes in developing rats. Epilepsy Behav 2: 473-480, 2001.

MAREŠ P, MAREŠOVÁ D, TROJAN S, FISCHER J: Ontogenetic development of rhythmic thalamo-cortical phenomena in the rat. Brain Res Bull 8: 765-769, 1982.

MAREŠ P, ROKYTA R, TROJAN S: Epileptic seizures during ontogenesis in the rat. J Physiol (Paris) 78: 863-864, 1982-1983.

MAREŠOVÁ D, MAREŠ P: Dizocilpine pretreatment suppresses the action of hypoxia on hippocampal epileptic afterdischarges in immature rats. Physiol Res 48: 389-394, 1999.

MAREŠOVÁ D, RILJAK V, MAREŠ J: Melatonin modulates hypoxia-induced changes of rat brain excitability. Gen Physiol Biophys 29: 67-71, 2010.

MOSHE SL, STANTON PK, SPERBER EF: Sensitivity of the immature nervous system to epileptogenic stimuli. In: Epilepsy: Models, Mechanisms and Concepts. SCHWARTZKROIN PA (ed), Cambridge University Press, Cambridge, 1993, pp 171-198. 
NAI Q, MCINTOSH JM, MARGIOTTA JF: Relating neuronal nicotinic acetylcholine receptor subtypes defined by subunit composition and channel function. Mol Pharmacol 63: 311-324, 2003.

PELISSIER AL, GANTENBEIN M, BRUGUEROLLE B: Chronopharmacological effects of nicotine repeated administration on heart rate, body temperature and locomotor activity circadian rhythms in rats. Life Sci 63: 2189-2197, 1998.

RILJAK V, MILOTOVÁ M, JANDOVÁ K, POKORNÝ J, LANGMEIER M: Morphological ganges in the hippocampus following nicotine and kainic acid administration. Physiol Res 56: 641-649, 2007.

RILJAK V, MAREŠOVÁ D, POKORNÝ J: Nicotine effects on rat seizures susceptibility and hippocampal neuronal degeneration. Neuro Endocrinol Lett 31: 792-795, 2010.

RILJAK V, MAREŠOVÁ D, DOHNALOVÁ A, POKORNÝ J: Nicotine influences the motor performance of immature rats in two different sensorimotor tasks. Prague Med Rep 112: 177-183, 2011.

ROLE LW, BERG DK: Nicotinic receptors in the development and modulation of CNS synapses. Neuron 16: $1077-$ $1085,1996$.

SCHMUED LC, HOPKINS KJ: Fluoro-Jade B: a high affinity fluorescent marker for the localization of neuronal degeneration. Brain Res 874: 123-130, 2000.

SCHWARTZKROIN PA: Epileptogenesis in the immature CNS. In: Electrophysiology of Epilepsy. SCHWARTZKROIN PA, WHEAL HV (eds), Academic Press, New York, 1984, pp 389-419.

SOOD N, HOTA D, SAHAI AK, CHAKRABARTI A: Nicotine reversal of anticonvulsant action of topiramate in kainic acid-induced seizure model in mice. Nicotine Tob Res 13: 1084-1091, 2011.

SPERK G: Kainic acid seizures in the rat. Prog Neurobiol 42: 1-32, 1994.

STAFSTROM CE, THOMPSON JL, HOLMES GL: Kainic acid seizures in the developing brain: status epilepticus and spontaneous recurrent seizures. Brain Res Dev Brain Res 65: 227-236, 1992. 